\title{
Medicina Geral e Familiar: Desafios Hoje e no Futuro
}

\author{
General Practice and Family Medicine: Challenges Today and in the Future
}

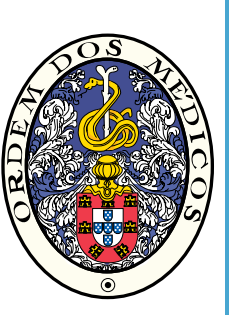

José Silva HENRIQUES ${ }^{1,2}$, Denise ALEXANDRA ${ }^{3}$

Acta Med Port 2014 May-Jun;27(3):287-288

Palavras-chave: Medicina Geral e Familiar; Portugal.

Keywords: Family Practice; General Practice; Portugal.

\section{INTRODUÇÃo}

Terá a Medicina Geral e Familiar (MGF) futuro ou é um 'anacronismo indesejado'? ${ }^{1}$

Terá a MGF lugar numa sociedade cada vez mais individualista, dependente de tecnologias, exigindo mais e maior especialização, com maior acesso a informação, mais exigente e reivindicativa?

Desde a criação, em Portugal, desta Especialidade, nos anos 80 do século $X X$, tem havido períodos de evolução, intercalados com períodos de quase marasmo. Recentemente, e após um período de perda de apoio político, protagonismo e financiamento dos CSP, contra uma 'oposição encarniçada do status quo', ${ }^{2}$ a única reforma estruturante, de qualidade e inovadora nos serviços públicos, foi a realizada nos Cuidados de Saúde Primários (CSP), com a implementação de modelos organizacionais mais ágeis, atrativos, com boa resposta às necessidades de saúde das populações e boa relação custo-eficácia (as Unidades de Saúde Familiar - USF). Apesar disso, uma auditoria ao desempenho das unidades de CSP, feita recentemente pelo Tribunal de Contas, apresentou conclusões que poderiam apoiar uma decisão política para acabar com estes modelos organizacionais (USF, principalmente modelo B). Estamos a falar dum poder político irresponsável ou mal assessorado, que governa através de medidas de curto prazo e economicistas.

A MGF tornou-se reconhecida pelos portugueses, pelos jovens médicos, muitos escolhendo enveredar pela especialidade, e pela Academia. A MGF alcançou uma imagem credível e de confiança junto da população. Oferece às populações uma Medicina de qualidade e proximidade, dando resposta às suas necessidades de mais e melhor saúde. Ter o seu Médico de Família (MF), e não um médico assistente, é uma necessidade sentida por muitos portugueses. No entanto, falta ainda, às populações, uma voz e um papel mais ativo nas soluções para os seus problemas de saúde, papel ainda incipiente nas organizações de saúde onde estão inscritas (USF e UCSP).

A MGF é uma especialidade que tem vindo a conquis- tar as preferências das novas gerações de médicos. Um estudo de 2009 mostrou que, para uma percentagem elevada $(78,9 \%)$, a MGF 'foi a sua primeira opção, na altura da escolha da especialidade'. ${ }^{3}$ Isto deve-se à instituição do ensino pré-graduado da MGF nas Escolas de Medicina portuguesas, a um Internato bem estruturado, e à existência de Órgãos, Sociedades Científicas e vasta publicação de conhecimento produzido nesta área médica. Presentemente, as oito Escolas Médicas portuguesas têm Departamentos / Disciplinas de MGF e os 'doutoramentos e mestrados na área da medicina geral e familiar também se têm vindo a multiplicar'. ${ }^{4}$

A Direção do Colégio está a rever o programa de formação específica, em colaboração com as Coordenações do Internato, conforme plasmado no art. $28 .^{\circ}$ do Regulamento do Internato Médico, que refere 'Os programas de formação (...) devem ser revistos de cinco em cinco anos pela Ordem dos Médicos'. ${ }^{5}$

Internacionalmente, o programa de formação específica é reconhecido como estando bem estruturado e com qualidade, o mesmo acontecendo às novas formas organizacionais (USF e muitas das Unidades de Cuidados de Saúde Personalizados - UCSP), onde a especialidade é exercida.

\section{O PRESENTE E O FUTURO DA MGF}

A MGF tem responsabilidade no desenvolvimento de estratégias que levem, mas também ao aumento da esperança média de vida das pessoas, mas também ao aumento do que muitos chamam a 'esperança de saúde' - o número de anos em que levaremos uma vida saudável sem condições debilitantes ou doenças. Sabemos que a maior parte do grande aumento da esperança média de vida dos seres humanos nos últimos cem anos deve-se a melhorias no saneamento básico, na nutrição e aos avanços na medicina' ${ }^{6}$ nas áreas preventiva, curativa, imagiológica e de reabilitação. Também sabemos que os estilos de vida são vetores fundamentais para o binómio saúde - doença e para o processo de envelhecimento. Assim, a pre-

\footnotetext{
1. Presidente. Colégio da Especialidade de Medicina Geral e Familiar. Ordem dos Médicos. Lisboa. Portugal.

2. Departamento de Medicina Geral e Familiar. Unidade de Saúde Familiar de S. Félix da Marinha. Vila Nova de Gaia. Portugal.

3. Departamento de Medicina Geral e Familiar. Unidade de Saúde Familiar de Santiago. Leiria. Portugal.
}

Recebido: 22 de Abril de 2014 - Aceite: 05 de Maio de 2014 | Copyright @ Ordem dos Médicos 2014 
venção e a promoção da saúde têm de ter um papel central no ensino pré-graduado, na formação pós-graduada, e na prestação de cuidados pelos especialistas de MGF. Relativamente aos rastreios, o MF tem de estar informado e cultivar um espírito crítico para não correr o risco de transformar indivíduos saudáveis em 'doentes'. Muitas das intervenções nos nossos pacientes serão desnecessárias e dispendiosas. Por isso, o MF tem de estar atualizado, ter experiência e desenvolver o raciocínio clínico e a capacidade de decisão. Isto também é verdade quando o MF tem de aplicar múltiplas Normas de Orientação Clínica (NOC). As NOC permitem que o médico esteja informado e apoiado na tomada de decisão, mas devem ser aplicadas prudentemente, alicerçadas no paradigma de que o MF não trata doenças, mas doentes. As auditorias feitas às NOC são importantes para a melhoria contínua dos serviços, se feitas por quem sabe, com rigor e transparência. 'Da forma como têm decorrido, em que muitos dos parâmetros auditados nas auditorias estão mal definidos, não têm importância clínica, não estão explicitados nas NOC e não são registáveis nos programas informáticos de registo clínico', ${ }^{7}$ leva a que o seu 'incumprimento' seja elevadíssimo(!), levando a taxas anormalmente elevadas de aparente 'desconformidade', taxas essas que não têm qualquer significado ou relevância médica mas que causam alarme na população e desprestigiam o processo. Sublinhe-se que estes parâmetros não foram analisados nem validados previamente com a Ordem dos Médicos, incumprindo o disposto no protocolo. ${ }^{7}$

O especialista de MGF deve ter, cada vez mais, conhecimentos e treino na área da informática. $A$ informatização dos ficheiros clínicos é um processo importante, mas apresenta paradoxos. É útil para melhorar os cuidados prestados, proporcionar investigação e ensino e reduzir despesa, mas, como é informação valiosa para algumas entidades, pode ser devassada, com prejuízos para os utentes. Outro paradoxo é o risco de se criar uma 'barreira' entre o médico e o paciente, principalmente fruto do excesso de indicadores impostos pela tutela, muitos sem ganhos de saúde para as populações.

O futuro da MGF, se queremos que tenha futuro, tem de

\section{REFERÊNCIAS}

1. Haslam D. Introduction. The future of general practice. A statement by the Royal College of General Practitioners. London: Royal College of General Practitioners; 2014.

2. Biscaia A. Futurar em positivo. Satisfação no trabalho. Agualva-Cacém: Grafisol - Edições e Papelarias, Lda; 2013.

3. Gaspar D. Internato médico de medicina geral e familiar - quem somos? O perfil do médico interno de medicina geral e familiar, em Portugal. Acta Med Port. 2010;23:39-50.

4. Sousa JC, Sardinha AM, Perez Y, Sanchez J, Melo M, Ribas MJ. Os cuidados de saúde primários e a medicina geral e familiar em Portugal. passar pela sua adaptação, acompanhamento e atualização nos avanços feitos a nível da fisiologia e anatomia, da psicologia e psicopatologia, da farmacologia e terapêutica, da bioestatística e das ciências humanas, como a antropologia, a sociologia e a bioética. Não pode estar presa ao passado. Querer manter tudo como antes, incapazes de projetar o futuro, não serve o futuro da MGF.

A MGF, como disciplina académica e especialidade médica, deve 'ganhar profundidade', maior 'autoconsciência' e 'afirmar-se cada vez mais como uma área da Medicina que cuida, trata e investiga o indivíduo como um todo e na sua universalidade'. ${ }^{2}$

\section{CONCLUSÃO}

Concluímos com duas constatações e uma resposta. A primeira constatação é que se vem evidenciando a perda de 'autonomia organizativa'8 e de gestão das USF, reconhecida legalmente pelo Decreto-Lei n. ${ }^{\circ}$ 298/2007 de 22 de Agosto, em detrimento de uma ingerência destas Unidades de Saúde por parte das estruturas diretivas dos Agrupamentos de Centros de Saúde (ACeS). As USF deviam ter autonomia para contratarem os seus profissionais, afetos ou não à Função Pública, através de critérios por si definidos e publicitados. A segunda constatação é que estão a transformar o exercício da MGF, intrinsecamente centrado na pessoa, numa medicina centrada em indicadores.

A resposta dirige-se às perguntas formuladas no início: a MGF tem futuro. A sociedade quer um especialista que resolva problemas de saúde de forma integrada, com qualidade, proximidade e melhor relação custo-efetividade. Esse especialista é o Médico de Família.

\section{CONFLITOS DE INTERESSE}

Os autores declaram não ter quaisquer conflitos de interesse relativamente ao presente artigo.

\section{FONTES DE FINANCIAMENTO}

Este trabalho não recebeu nenhuma contribuição de subsídio ou bolsa.

Rev Port Saúde Pública. 2001;2: 63-74.

5. Portaria $n .^{\circ} 251 / 2011$ de 24 de Junho. Ministério da Saúde. Diário da República, 1 a $^{\mathrm{a}}$ série - N. ${ }^{\circ} 120$ - 24 de Junho de 2011.

6. Gore AL. O futuro. Seis forças que irão mudar o mundo. Coimbra. Conjuntura Actual Editora; 2013.

7. Ordem dos Médicos. Suspensão da colaboração com as auditorias às Normas de Orientação Clínica. Porto: OM; 2014.

8. Decreto-Lei $n .^{\circ} 298 / 2007$ de 22 de agosto. (Ministério da Saúde. Decreto-Lei № 161. Diário da República, 1. ${ }^{a}$ série - N. ${ }^{\circ} 161$ - 22 de Agosto de 2007. 5587-96) 


\section{Medicina Geral e Familiar: Desafios Hoje e no Futuro}

Acta Med Port 2014:27:287-288

Publicado pela Acta Médica Portuguesa, a Revista Científica da Ordem dos Médicos

Av. Almirante Gago Coutinho, 151

1749-084 Lisboa, Portugal.

Tel: +351218428215

E-mail: submissao@actamedicaportuguesa.com

www.actamedicaportuguesa.com

ISSN:0870-399X | e-ISSN: 1646-0758

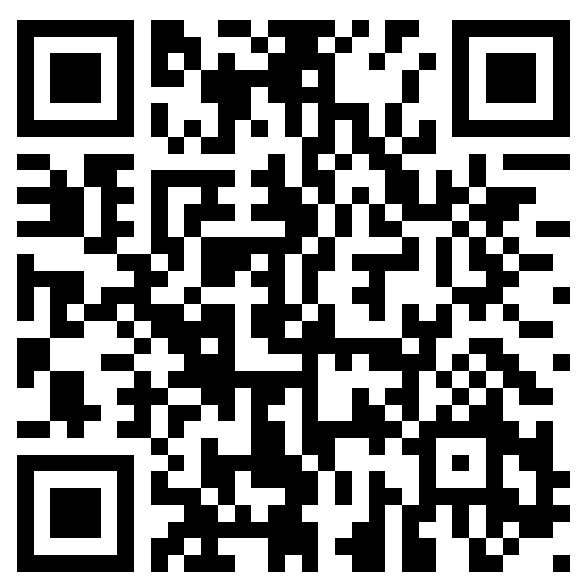

